ORIGINAL ARTICLE

\title{
Towards primary care for non-serious 999 callers: results of a controlled study of "Treat and Refer" protocols for ambulance crews
}

\author{
H Snooks, N Kearsley, J Dale, M Halter, J Redhead, W Y Cheung
}

Qual Saf Health Care 2004;13:435-443. doi: 10.1136/qshc.2003.007658

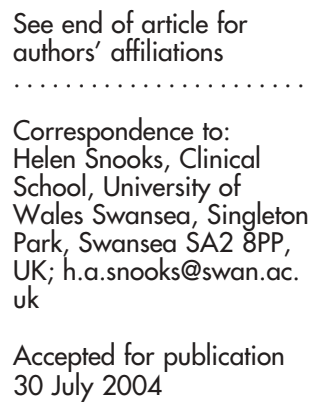

....................

\begin{abstract}
Objective: To develop and evaluate "Treat and Refer" protocols for ambulance crews, allowing them to leave patients at the scene with onward referral or self-care advice as appropriate.

Methods: Crew members from one ambulance station were trained to use the treatment protocols. Processes and outcomes of care for patients attended by trained crews were compared with similar patients attended by crews from a neighbouring station. Pre-hospital records were collected for all patients. Records of any emergency department and primary care contacts during the 14 days following the call were collected for non-conveyed patients who were also followed up by postal questionnaire. Results: Twenty three protocols were developed which were expected to cover over $75 \%$ of patients left at the scene by the attending crew. There were 251 patients in the intervention arm and 537 in the control arm. The two groups were similar in terms of age, sex and condition category but intervention cases were more likely to have been attended during daytime hours than at night. There was no difference in the proportion of patients left at the scene in the intervention and control arms; the median job cycle time was longer for intervention group patients. Protocols were reported as having been used in 101 patients $(40.2 \%)$ in the intervention group; 17 of the protocols were recorded as having been used at least once during the study. Clinical documentation was generally higher in the intervention group, although a similar proportion of patients in both groups had no clinical assessments recorded. 288 patients were left at the scene (93 in the intervention group, 195 in the control group). After excluding those who refused to travel, there were three non-conveyed patients in each group who were admitted to hospital within 14 days of the call who were judged to have been left at home inappropriately. A higher proportion of patients in the intervention arm reported satisfaction with the service and advice provided.

Conclusions: "Treat and Refer" protocols did not increase the number of patients left at home but were used by crews and were acceptable to patients. The protocols increased job cycle time and some safety issues were identified. Their introduction is complex, and the extent to which the content of the protocols, decision support and training can be refined needs further study.
\end{abstract}

unnecessary journeys to the ED may bring benefits for patients by providing appropriate care with less inconvenience; for the ambulance service by freeing up ambulances more quickly to attend other more serious cases; for crews by improved job satisfaction and reduced stress; and for the wider health service through more efficient and effective use of resources. However, the development of alternatives to transportation to the ED depends on the ability of emergency crews to make decisions to leave patients at the scene. Several studies exploring this issue have highlighted the difficulties of pre-hospital identification of patients' clinical needs. ${ }^{18-20}$ These studies have been shown in a recent review to be methodologically weak, with varying methods used to assess appropriateness of care and safety, and no randomised controlled trials have been completed in this field. ${ }^{21}$ However, preliminary results have raised concern, consistently showing a substantial risk for a small minority of patients $^{22}{ }^{23}$ and, indeed, one US trial was recently abandoned due to concerns about safety. ${ }^{24}$

Against this background, this study was set up to assess the effectiveness of implementing a new alternative to emergency transportation to the ED for non-serious 999 callers. The aim of the study was to develop and evaluate "Treat and Refer" (T\&R) protocols for ambulance crews which allowed them to leave patients at the scene with referral to community based services or self-care advice.

Implementing alternative responses to transportation to the ED has been advocated many times. ${ }^{2-6}$ Avoiding 
Box 1 UK ambulance response to emergency calls

Current performance standards

Emergency ambulance services are required to meet national performance standards, with calls triaged in the ambulance control room as:

- Category A (immediately life threatening): $75 \%$ to be attended within 8 minutes.

- Category B (serious) and Category C (neither life threatening nor serious): $90 \%$ to be attended in 14 minutes (19 minutes in rural areas).

\section{Current 999 response}

Immediate despatch of an emergency ambulance able to convey a patient which travels to the incident with flashing lights and sirens, with two trained personnel, either emergency medical technicians or paramedics, with Advanced Life Support (ALS) qualifications.

If the patient's condition is immediately life threatening an EMT or paramedic in a response unit without ability to convey usually also attends.

If the patient's condition is triaged as less serious, an EMT or paramedic may telephone the patient, in place of an ambulance response, to determine if another form of care is appropriate. Alternative response vehicles and staff educated specifically for these callers are in development (not in place at time of the study).

Indicators of effectiveness were set up to measure the operational effects on the emergency care system, as well as the quality and safety of care delivered to patients, from the perspective of patients as well as using clinical measures.

\section{METHODS}

\section{Study design overview}

The study included both the development and testing of protocols. During phase 1 the treatment protocols were drafted and agreed by a clinical panel. During phase 2 the crews from one ambulance station were trained to use the protocols and the new service was implemented for a trial period (intervention group). During this period processes and outcomes of care were assessed for patients meeting the study inclusion criteria attended by trained crews with similar patients attended and treated by crews working according to standard practice at a neighbouring station (control group).

\section{Study setting}

Both ambulance stations were in West London. The protocols were implemented between May and August 2000. The site was selected after extensive external and internal consultation as its crews were reported by local ambulance service managers as being receptive to participation in the study. It was recognised from the outset that this new service would require partners to work together across the traditional boundaries of primary, secondary and social care, so a project steering group was set up with a wide membership in order to bring the perspectives of different service providers and commissioners, professional and patient groups to the study. This group met regularly throughout the study and provided advice and support at all stages.

\section{Development of protocols}

A multidisciplinary clinical panel made up of representatives from the London Ambulance Service (LAS) and local ED and
Session 1 (October 1999)
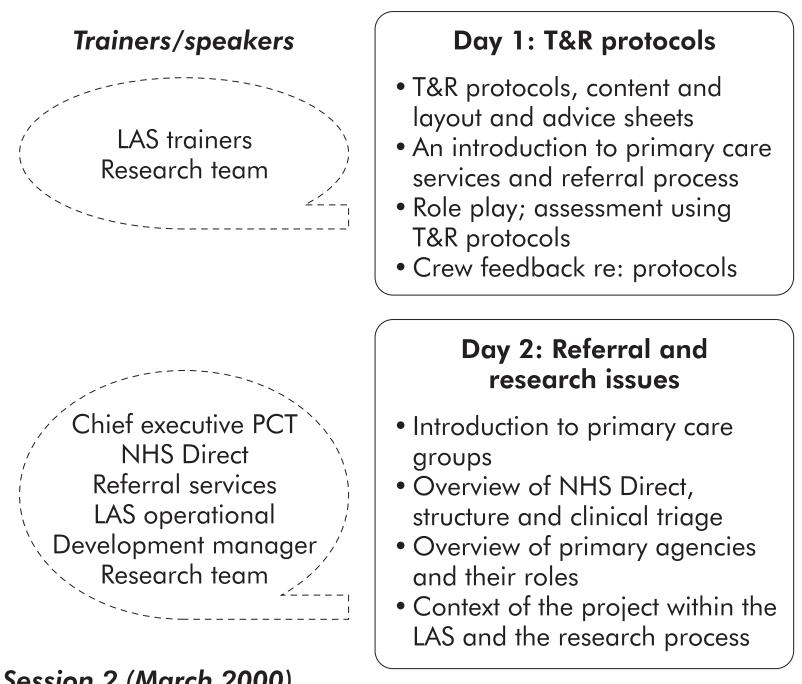

Session 2 (March 2000)

Workshop 1: T\&R protocols-
scenarios, data collection
- Overview of assessment
process and guidance around
the use of protocols
- Protocol based scenarios
- Data collection, completeness
and accuracy
- Issues raised by pilot work

Figure 1 Training sessions: delivery and content of initial and follow up workshops.

primary care services was formed to oversee the development of the protocols. A subgroup of ED consultants, the LAS Medical Director, a specialist registrar (JR), and a representative from the LAS training department met more frequently to draft and revise the detail of the protocols. The protocols were based on findings from:

- a review of previous research literature;

- a national survey of ambulance services to identify other initiatives concerning alternatives for patients with primary care needs (published separately ${ }^{25}$ );

- baseline local data collection at the two participating stations between June and September 1999: individual cases falling within illness codes with a high rate of nonconveyance were reviewed against the protocols developed to check coverage;

- routine LAS management information data concerning conveyance rates across the service.

\section{Crew training}

The intervention station crews (five paramedics and five EMTs) participated in a 2 day training course in October 1999 led by LAS trainers. The first day included a brief overview of the T\&R protocols and role play exercises based on the clinical conditions. The second day gave an overview of the new organisational arrangements being introduced (primary care trusts) to provide an improved community service. Representatives of several local agencies talked to the crews about their service and referral and assessment criteria. Senior managers from the LAS put the project into the context of service developments taking place and the need for research in this area. Research sessions were delivered by members of the research team and covered fundamentals of 
research methods, including the importance of recruiting a control group and the need for accurate documentation of patient care.

At the outset of the study no further training was envisaged but, due to identified needs, two additional half day workshops were put on in March 2000. This training was of a clinical nature and was led by the Medical Director of the LAS and the specialist registrar (JR) who had led the drafting of protocols (fig 1).

Clinical scenarios were used in the workshops to review the crews' assessment and decision making skills about conveyance. Emphasis was put on covering all the assessment criteria outlined in protocols and the taking of a consistent and systematic history including the measurement and documentation of clinical observations.

Each crew member underwent a competency assessment, with all crew members deemed competent to use the protocols for the trial.

\section{Study outcome measures}

In order to meet the first study objective-to assess the effects of the intervention on the emergency care systemthe primary outcome of the evaluation was set as the difference between the proportion of patients left at the scene by crews from the intervention station and those attended by crews from a neighbouring control station. As a secondary outcome concerned with operational impact, the interval between the 999 call and the ambulance reporting the case finished (job cycle time) was also compared between groups.

Further secondary outcomes aimed to assess the quality and safety of care delivered to patients included (1) frequency and patterns of protocol usage; and (2) completeness of clinical documentation. For the patients of most concern-that is, those who were not taken to hospitalcomparisons were made between the groups of (3) the number of patients admitted to hospital within 14 days of their emergency ambulance attendance who were judged to have been inappropriately left at the scene by their attending crew; and (4) patient satisfaction.

Identification of intervention and control group cases As it would have been inefficient to include all 999 patients in the study, a method was needed for identifying similar patients in each group who would be appropriate to leave at the scene that did not rely on crew selection. Locally collected baseline data concerning patterns of conveyance in the study area were used to identify illness codes (routinely assigned by ambulance crews on their patient report forms, completed for each individual patient they attend) that were most frequently given to patients who were left at the scene. These illness codes were used to identify patients for inclusion in each arm of the study.

Cases for which crews reported that they had used their new protocols but which fell outside of these illness codes are described but not included in the comparative analysis as they were not matched in the control group by any similar cases.

\section{Sample size calculation}

Based on activity levels before the trial, it was estimated that each week there would be approximately 50 cases meeting the study inclusion criteria. A sample size of 530 patients was aimed for in each arm of the study to give an $85 \%$ chance of detecting an increase in non-conveyance rate of $9 \%$ (from $35 \%$ to $44 \%$ ) at the $5 \%$ level.

\section{Data collection}

Patient report forms completed by ambulance crews were collected for all cases included in the study. Cases were

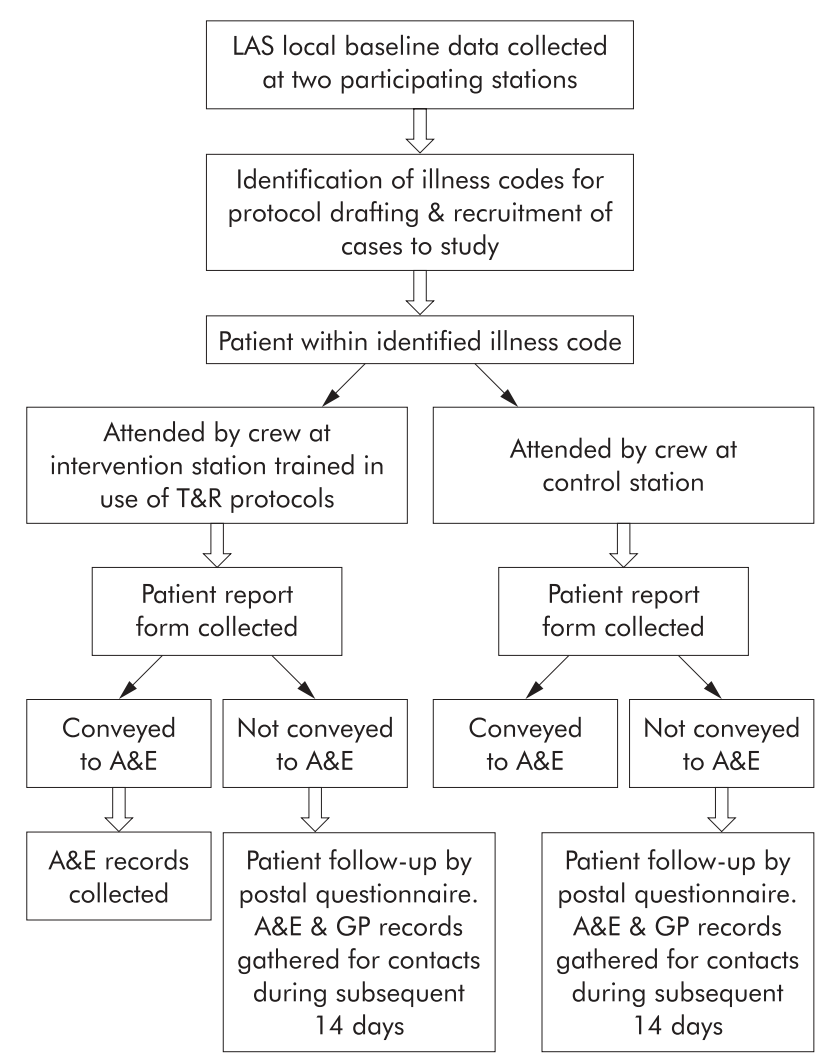

Figure 2 Data collection processes: flow chart.

reviewed by JR to assess whether protocols were used appropriately. A second clinician (ED consultant/Medical Director of LAS) independently assessed protocol usage for $15 \%$ of the intervention patients to assess inter-rater reliability. ED records were collected for all patients taken there, and these were reviewed by JR for all patients discharged home with only basic or no care.

Follow up data were collected on patients who were left at the scene from ED and GP records and by postal questionnaire. The patient questionnaire (modified version of the "Quality of Care Monitor"26) measured patient satisfaction and health service usage in the 14 days following the incident.

All non-conveyed cases identified as having been admitted to hospital in the 14 days after the 999 call were reviewed by two local ED consultants who were asked to judge whether non-conveyance was appropriate at the time of the 999 call and which (if any) protocols should have been used for intervention group patients.

Figure 2 illustrates the data collection processes.

\section{Use of routine management information}

In order to help us interpret our findings, once the illness codes had been identified for the trial, routinely collected management information was used to compare the proportions of patients not conveyed to hospital and job cycle times for cases meeting the identified codes for the two study stations and service wide for the same periods in the 2 years before the trial.

\section{Data analysis and research ethics approval}

The study illness codes were grouped into condition categories for the purposes of analysis. Binomial data were analysed by Fisher's exact test, other categorical data by a $\chi^{2}$ test with correction for continuity. Numerical data were 


\section{(21) SOCIAL PROBLEMS} (Draft 5)

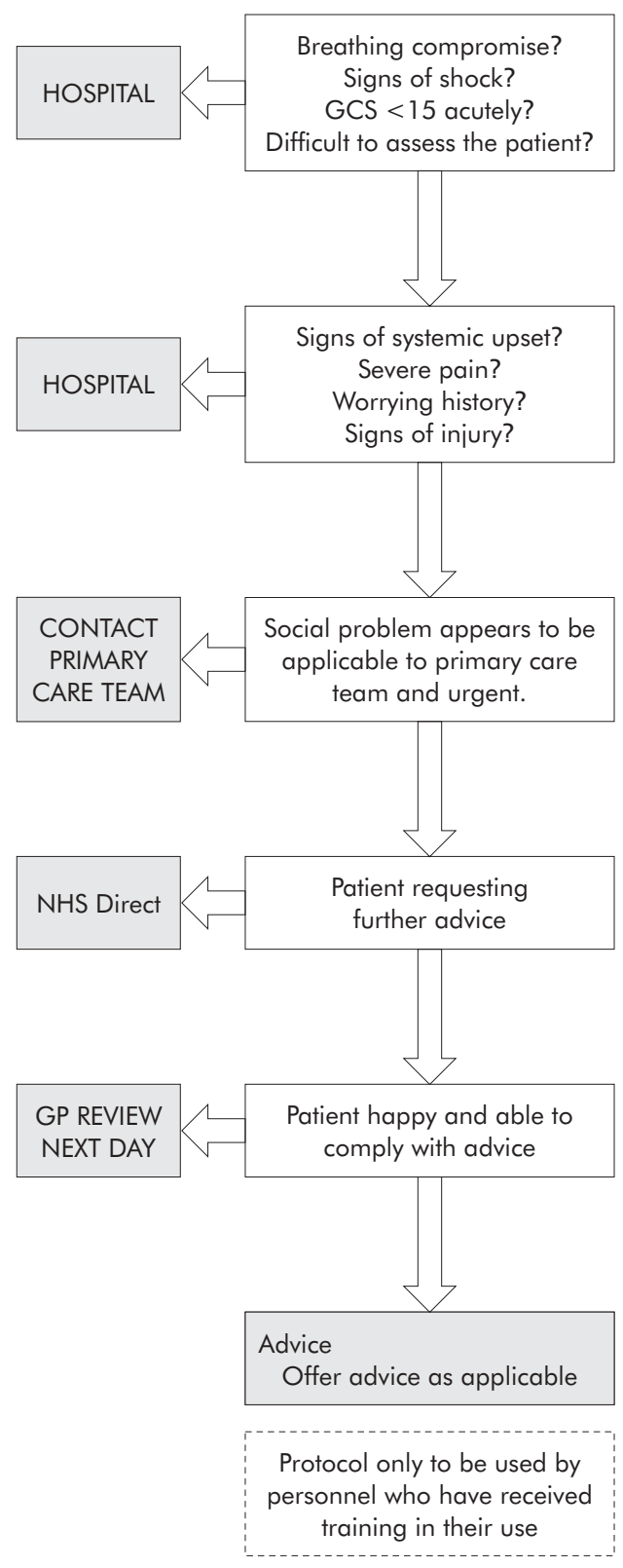

\section{Social problem}

The patient describes a problem which is not related to a medical condition, eg housing problem etc.

\section{Breathing compromise}

Inability to maintain adequate oxygenation manifest by increased work of breathing, increased respiratory rate or exhaustion.

Signs of shock

These would include sweating; pallor; tachycardia or hypotension.

Difficult to assess patient

Any problem which prevents a proper assessment of your patient.

\section{Signs of systemic upset}

Anything during the assessment of the patient which would suggest another coexisiting acute pathology such as infection. Check:

Temperature

Dehydration

Vomiting

\section{Severe pain}

The patient is complaining of or exhibiting signs of pain which would be unlikely to respond to oral analgesia or settle with simple treatment.

\section{Worrying history}

A history which does not fit with the condition of the patient OR the patient has a past medical history or drug history which you feel may have a bearing on the management of the condition.

Check:

Warfarin

Social isolation

Immunosuppression

\section{Signs of injury}

The patient has any bruising or lacerations around the head or the history suggests a possible head injury. Any other indications that the patient has sustained an injury which requires further attention.

\section{Contact primary care team}

Contact with the General Practitioner or District Nurse is appropriate for further advice. If a visit is appropriate but you feel or the patient feels unable to wait for the estimated time of arrival then transfer to the Accident and Emergency is appropriate.

\section{NHS Direct}

Provide the patient with the telephone number of NHS Direct.

\section{GP review the next day}

All patients should be advised to contact their GP the next day for further advice.

Figure 3 Example of "Treat and Refer" protocol.

analysed using the Mann-Whitney $U$ test. Inter-rater reliability was assessed with Cohen's kappa.

Approval for the study was granted by the local research ethics committees for the area.

\section{RESULTS}

\section{Baseline operational indicators}

Pre-study routine management information from the same months in 1998 and 1999 showed that non-conveyance rates for cases meeting the study inclusion criteria were significantly higher at the study stations than service wide (1998: intervention station $34 \%$, control station $37 \%$, service wide $23 \%, \mathrm{p}<0.001$; 1999: intervention station $32 \%$, control station $32 \%$, service wide $24 \%, \mathrm{p}<0.001$ ). However, there was no significant difference between the intervention and control stations (1998: $34 \% \vee 37 \%, \mathrm{p}=0.34 ; 1999$ : $32 \% v$ $32 \%, \mathrm{p}=1.0$ ). Both stations had relatively short mean job cycle times for non-conveyed cases (1998: intervention station 44 minutes, control station 46 minutes, service wide 51 minutes; 1999: intervention station 46 minutes, control 
Table 1 Cases matching the "Treat and Refer" (T\&R) protocols by illness code from the locally collected 3 month pre-trial dataset

\begin{tabular}{ll}
\hline LAS illness code & $\begin{array}{l}\text { No (\%) of cases that } \\
\text { matched T\&R } \\
\text { protocols }\end{array}$ \\
\hline No injury or illness & $232(78)$ \\
Minor cuts and bruises & $76(100)$ \\
Alcohol related & $38(100)$ \\
Minor injuries (other) & $35(100)$ \\
Diabetic & $32(100)$ \\
Fainted, dizziness, loss of & $23(100)$ \\
coordination & \\
Epileptic fit & $20(100)$ \\
Hyperventilation/panic & $20(100)$ \\
Pain(s) back & $15(100)$ \\
Generally unwell & $12(35)$ \\
Confused, distressed, upset & $10(91)$ \\
Unable to cope & $8(100)$ \\
Other medical condition & $8(29)$ \\
Pain, other & $5(28)$ \\
Psychiatric problem diagnosed & $5(63)$ \\
Psychiatric problem undiagnosed & $5(83)$ \\
Abdominal pains & $4(25)$ \\
Diarrhoea & $3(100)$ \\
(Vomiting) & $2(100)$ \\
Sprains/strains & $2(100)$ \\
Collapse & $1(100)$ \\
Other & $8(13)$ \\
Total & $564(75)$ \\
\hline & \\
\hline
\end{tabular}

station 46 minutes, service wide 55 minutes), again with no difference between the sites.

\section{Protocol development}

Twenty three protocols were developed (box 2), intended for active use during the patient care process and including decision points for transportation to the ED, referral to other agencies, or self-care (fig 3). For any individual patient, all protocols appropriate to the presented problem were required to be used, in conjunction with one another if necessary. Together, the protocols covered the problems documented as presented for $75 \%$ of the cases that had not been conveyed to hospital in the locally collected baseline data (table 1).

\section{Main trial: sample details}

From the baseline data collected at the study sites, 24 illness codes were selected to be used to identify patients to be included in the study. The primary and secondary outcomes depended on data collected from within the ambulance service and, to our knowledge, complete retrieval was achieved. In all, 797 patients were included in the study: 251 in the intervention group (attended by a crew member trained to use the new protocols with a condition that fell within the study illness codes); 537 in the control group (attended by a crew from the control station, with a designated study illness code and treated according to standard practice); and nine attended by trained crews but with a condition outside the designated illness codes and therefore excluded from the comparative analysis.

There were no statistically significant differences between the intervention and control groups in age ( $54 v 47$ years, $\mathrm{p}=0.08,95 \% \mathrm{CI}$ of difference 0 to 7$)$, sex ( $52 \%$ v $51 \%$ male, $\mathrm{p}=0.69,95 \%$ CI of difference -5 to 8 ), or condition category of patients $\left(\chi^{2}=15.23, \mathrm{p}=0.06\right)$, with the most common problems in each group being falls $(29.6 \% v 22.9 \%)$, generally unwell/medical problems ( $17.3 \% v 18.2 \%)$, and minor injuries $(14.6 \% \vee 12.1 \%)$. There were differences in the temporal distribution of calls, with intervention group patients somewhat more likely to have been attended during daytime hours

\section{Box 2 "Treat and Refer" protocols $(n=23)$}

- Minor allergic reactions

- Insect bites and stings

- Boils/abscesses

- Splinter removal

- Postoperative wound problem

- Dressing problem

- Wounds (minor)

- Soft tissue injuries (minor)

- Epistaxis

- Sore throat

- Cold or flu symptoms

- Toothache

- Fit (= seizure) in known epileptic

- Resolved hypoglycaemia in known diabetic (insulin dependent)

- Back pain

- Diarrhoea

- Constipation

- Blocked urinary catheter

- Emotional or hysterical reaction

- Alcohol intoxication

- Social problems

- Faints

- Falls

than at night $(61 \% v 52 \%, \mathrm{p}=0.02,95 \% \mathrm{CI}$ of difference 2 to 15).

\section{Main trial: primary outcome}

There was no significant difference in the proportion of patients left at the scene in the intervention and control groups (93/251 (37.1\%) v 195/537 (36.3\%), p = 0.90, 95\% CI of difference -6 to 7 ).

\section{Main trial: secondary outcomes \\ Protocol usage}

Protocols were recorded as having been used for 101 of the 251 patients in the intervention group $(40.2 \%)$ and for nine other patients who fell outside the study inclusion illness codes. All eight crew members who were trained to use the protocols recorded having used them, although the proportion of patients seen during the study period for whom they did this varied widely (mean $42 \%$, range $11-100$ ). Seventeen of the 23 protocols were reported as having been used during the study, with the falls protocol used far more than any other (57 times). The next most frequently used was soft tissue injury (9 times).

Table 2 Median job cycle times

\begin{tabular}{llll}
\hline & $\begin{array}{l}\text { Conveyed } \\
\text { (minutes) }\end{array}$ & $\begin{array}{l}\text { Non-conveyed } \\
\text { (minutes) }\end{array}$ & $\begin{array}{l}\text { p value } \\
(95 \% \mathrm{Cl} \text { of } \\
\text { difference) }\end{array}$ \\
\hline Intervention & 59 & 35 & $\begin{array}{l}<0.0001 \\
(18 \text { to } 26) \\
<0.0001 \\
(24 \text { to 29) }\end{array}$ \\
\hline
\end{tabular}


Table 3 Documentation of assessments in all patients $(n=795)$

\begin{tabular}{lllll}
\hline Assessment & $\begin{array}{l}\text { Intervention cases } \\
(\%)\end{array}$ & $\begin{array}{l}\text { Control cases } \\
(\%)\end{array}$ & $\begin{array}{l}\mathbf{9 5 \%} \mathbf{C l} \\
\text { of difference }\end{array}$ & p value \\
\hline $\mathrm{O}_{2}$ saturation & 34 & 6 & 39 to 57 & $<0.0001$ \\
Pulse rate & 56 & 26 & 22 to 36 & $<0.0001$ \\
Blood pressure & 56 & 13 & 41 to 55 & $<0.0001$ \\
Respiratory rate & 19 & 56 & -3 to 15 & 0.21 \\
Glasgow Coma Scale & 61 & 20 & -2 to 11 & 0.20 \\
Pupil check & 30 & 5 & 4 to 20 & $<0.005$ \\
Blood glucose & 15 & 38 & 17 to 41 & $<0.0001$ \\
No vital signs recorded & 35 & & -10 to 4 & 0.46 \\
\hline
\end{tabular}

On retrospective review of crew patient report forms, JR judged a further 74 cases $(29.5 \%)$ to have been appropriate for protocol usage, and three (1.2\%) for which a protocol was documented as having been used to have been inappropriate for protocol usage. Hence, of the 181 patients treated by trained crews and deemed suitable for assessment with a protocol, crews recorded having done so for 107 (59.1\%) of them. Independent assessment of a sample of cases by a second clinician showed moderate but significant agreement with the first assessment (seven discordant pairs and 30 concordant pairs, kappa $=0.55, \mathrm{p}=0.001$ ).

In 93/156 (59.6\%) conveyed patients in the intervention group, A\&E department records could be located who did not wait, self-discharged, or were discharged home; 36 (38.7\%) of these patients received no investigations and no or only minor treatment (Steristrips, written/verbal guidance, oral analgesia, other oral drugs). Crews had used their protocols for 17 of the 36 cases and a review by JR indicated that six more patients may have been appropriate for protocol use.

Job cycle times

The median job cycle time was 4 minutes longer for intervention than control group patients (51 v 47 minutes; $\mathrm{p}<0.001,95 \%$ CI of difference 2 to 9). As shown in table 2, in both groups the median job cycle time was considerably longer for patients who were conveyed than for those not conveyed. However, the median job cycle time was 8 minutes longer for non-conveyed patients in the intervention group than in the control group ( 35 minutes $v$ 27 minutes, $\mathrm{p}<0.0001,95 \% \mathrm{CI}$ of differences 5 to 11 ).

\section{Clinical documentation}

Overall, as shown in table 3, clinical observations were more comprehensively documented in the intervention group. However, a similar proportion of patients in both groups had no clinical assessments recorded at all.

\section{Patients who were not conveyed to ED: further analysis \\ Response rates and missing data}

As summarised in table 4, after excluding repeat callers, patients who lived outside the study area and those without sufficient detail for contact, 117/215 (54.4\%) of those invited to participate completed a follow up questionnaire. Data on subsequent care were retrieved from GPs and local ED clinical records for a further 36 patients (16.7\%), but there remained

\begin{tabular}{|c|c|c|c|}
\hline Follow up: route and outcome & $\begin{array}{l}\text { Intervention group } \\
(\mathrm{n}=93)\end{array}$ & $\begin{array}{l}\text { Control group } \\
(n=195)\end{array}$ & $\begin{array}{l}\text { Overall } \\
(n=288)\end{array}$ \\
\hline \multicolumn{4}{|l|}{ Patient postal follow up } \\
\hline Excluded & 23 & 50 & 73 \\
\hline Repeat calls & 8 & 16 & 24 \\
\hline Address outside area & 0 & 1 & 1 \\
\hline Insufficient details & 15 & 33 & 48 \\
\hline Sent invitation & 70 & 145 & 215 \\
\hline Refused & 13 & 25 & 38 \\
\hline Sent questionnaire & 57 & 120 & 177 \\
\hline Completed & 38 & 79 & 117 \\
\hline Refused & 1 & 5 & 6 \\
\hline No reply & 18 & 36 & 54 \\
\hline$\%$ response rate (completed/sent invitation) & 54.3 & 54.5 & 54.4 \\
\hline \multicolumn{4}{|l|}{ GP follow up } \\
\hline Excluded & 35 & 86 & 122 \\
\hline No GP details & 10 & 34 & 45 \\
\hline Outside study area & 3 & 5 & 8 \\
\hline Patient in armed forces & 1 & 0 & 1 \\
\hline Patient refused to participate & 15 & 30 & 45 \\
\hline Other (including repeat calls) & 6 & 17 & 23 \\
\hline Sent questionnaire & 56 & 109 & 166 \\
\hline Returned completed & 49 & 69 & 118 \\
\hline No reply & 7 & 40 & 48 \\
\hline$\%$ response rate (completed/sent questionnaire) & 87.5 & 63.3 & 71.1 \\
\hline \multicolumn{4}{|l|}{ Hospital follow up for non-responders } \\
\hline Total followed up at A\&E & 20 & 53 & 73 \\
\hline No follow up information gained & 18 & 44 & 62 \\
\hline $\begin{array}{l}\% \text { overall response rate (some information } \\
\text { retrieved/total non-conveyed) }\end{array}$ & 80.7 & 77.4 & 78.5 \\
\hline
\end{tabular}


Box 3 Non-conveyed cases for which protocols were reported to have been used and judged by the A\&E reviewers to have warranted conveyance at the time of the call out

Case 1 (78 year old woman living at home with son) Presenting problem (time of call: 02:55): fall ?injury. Slipped, twisting and falling backwards against wall. Son had already contacted NHS Direct for advice.

Assessment: chief complaint pain (on movement), central lumbar top of right hip bone. Past medical history, arthritis. Patient in bed, no apparent injuries. Contacted NHS Direct to triage and refer to GP.

T\&R protocol 23 (falls): the crew's assessment "did not indicate conveyance" to A\&E

Referral: NHS Direct, triage (time 03:22). Muscular skeletal backache, onset $<3$ hours, location lower back, pain moderate, radiation left buttock, mechanism fall, treatment analgesia, bowel movement normal, micturition normal. Triaged as moderate urgency care, GP visit within 24 hours.

Follow up: On-call GP attended (time 04:15). O/E tender over lower sacrum, no $\mathrm{T} / \mathrm{L}$ spinal tenderness, no neurology, hips NAD, reassurance, analgesia for the time being, will ring GP for follow up. Seen by own GP in the morning and admitted to hospital.

Admission: Same day A\&E via emergency ambulance. Complaining of severe neck and lower back pain, now unable to get out of bed, tender C3.

Outcome: orthopaedic admission, fracture; length of stay 35 days.

Consultant review: T\&R protocols to be used: (1) 23 "falls" and (2) 15 "lower back pain". Assessment criteria of protocol should have led to admission "worrying injury, patient unable to mobilise". (No indication of inquiring or advising analgesia.)

Case 2 (63 year old woman living in warden controlled sheltered accommodation)

Presenting problem (time of call 09:01): fall ?injuries.

Assessment. no injuries. Past medical history, known alcoholic.

T\&R protocol 20 (alcohol intoxication): the crew's assessment "did not indicate conveyance" to A\&E.

Referral: crew referred to GP.

Follow up: GP attended within 24 hours, home visit, and referred to $\mathrm{DN} /$ social services, prescribed medications.

Admission: next day found on floor by warden, not able to mobilise. Taken to A\&E via emergency ambulance.

Diagnosis: (1) Acopia, frequent falls; (2) jaundiced and abnormal liver function tests (secondary to alcohol abuse).

Outcome: medical admission; length of stay 11 days.

Consultant review: T\&R protocols 23 ("falls") to be used. Admission does not appear to be related to fall; however assessment criteria should have led to conveyance to A\&E, criteria met "worrying history, worrying frequency".

$62(28.9 \%)$ for whom no follow up information could be retrieved.

\section{Patient safety}

Five of the 93 patients $(5.4 \%)$ in the intervention group and 12 of the $195(6.2 \%)$ in the control group were identified who had been left at home and were admitted to hospital in the 14 days after the 999 call. After excluding patients who refused to travel, the clinical reviewers judged that three patients in each group should have been taken to the ED at the time of the 999 call. Crews had reported using protocols for two of those in the intervention group, but the ED reviewers judged from the details of the condition of the patient on scene and the ED records that additional protocols should have been used and that use of these protocols would have led to a decision to convey to an ED (see case reviews 1 and 2, box 3).

Only two of the nine patients assessed with protocols who were outside the study inclusion illness codes were left at home and neither of these was identified as having been subsequently admitted to hospital.

\section{Patient satisfaction}

A higher percentage of non-conveyed patients in the intervention group strongly agreed that their ambulance crew gave them the right amount of advice (69\% $v 46 \%$, $\mathrm{p}<0.05)$; that they were reassured by the advice $(72 \% \vee 45 \%$, $\mathrm{p}<0.05)$; that they were given clear advice about when to get more help ( $71 \% \vee 47 \%, \mathrm{p}<0.05$ ); and that they were generally satisfied with the ambulance crew $(81 \% \vee 58 \%, \mathrm{p}<0.05$; table 5).

\section{DISCUSSION}

\section{Summary of key findings}

Operational impact

This study failed to demonstrate a change in the primary outcome measure (the proportion of patients not conveyed to hospital) associated with the introduction of "Treat and Refer" protocols. However, the intervention was found to have an operational impact through increased job cycle times.

\section{Quality and safety of care}

Although the protocols were used to some extent by all the crew members trained in their use, retrospective review of cases suggested that there was potential both for further use of existing protocols and for development of new protocols. Overall, documentation of clinical assessments was higher in the intervention group than in the control group.

Concerns were identified with the safety of current usual practice and of practice using the protocols. High rates of satisfaction were reported in both groups, although satisfaction with some aspects of care-particularly those related to communication of advice-showed higher levels in the intervention group than those attended by crews from the control station acting according to their usual practice.

\section{Study limitations}

Study design

There were a number of constraints on the design and implementation of the study. Because of the nature of the intervention which necessitated training of crews to use new protocols and the operational requirements of an ambulance service, it was impractical to set up a study in which patients could be randomly allocated to study groups. Hence, the study design was to track two cohorts of patients that were attended by crews over the same period. Adjacent stations were selected for pragmatic reasons to increase the comparability of the two groups, with the two stations serving similar populations in terms of socioeconomics and geography. However, overlap of station patient catchment areas and receiving hospitals meant possible contamination caused by crew interaction.

\section{Site selection}

As the study site was selected due to the anticipated compliance of crews, lower levels of compliance might be seen if protocols were introduced elsewhere. On the other hand, historical data showed that the study sites had relatively high non-conveyance rates and short job cycle 
Table 5 Patient satisfaction scores by study group

\begin{tabular}{|c|c|c|c|}
\hline \multirow[b]{2}{*}{ Satisfaction items } & Intervention group & Control group & \multirow[b]{2}{*}{$\begin{array}{l}\mathrm{p} \text { value }(95 \% \mathrm{Cl} \\
\text { of difference) }\end{array}$} \\
\hline & $\begin{array}{l}\% \text { (n/N) } \\
\text { strongly agree }\end{array}$ & $\begin{array}{l}\%(\mathrm{n} / \mathrm{N}) \\
\text { strongly agree }\end{array}$ & \\
\hline $\begin{array}{l}\text { Ambulance crew listened very carefully } \\
\text { to my problem }\end{array}$ & $63 \%(22 / 35)$ & $51 \%(37 / 72)$ & $0.30(-7$ to 27$)$ \\
\hline Crew were very polite & $70 \%(26 / 37)$ & $62 \%(47 / 76)$ & $0.41(-10$ to 26$)$ \\
\hline Right amount of advice & $69 \%(24 / 35)$ & $46 \%(33 / 71)$ & 0.04 (2 to 37$)$ \\
\hline Reassured by the advice & $72 \%(23 / 32)$ & $45 \%(31 / 69)$ & 0.02 ( 6 to 41$)$ \\
\hline Satisfied with explanation & $69 \%(22 / 32)$ & $49 \%(33 / 67)$ & 0.09 (0 to 35$)$ \\
\hline Clear advice about when to get more help & $71 \%(22 / 31)$ & $47 \%(33 / 70)$ & 0.03 (3 to 38 ) \\
\hline \multirow[t]{2}{*}{ Generally satisfied with the ambulance crew } & $81 \%(30 / 37)$ & $58 \%(44 / 76)$ & 0.02 (6 to 39$)$ \\
\hline & $\begin{array}{l}\% \text { (n/N) strongly } \\
\text { disagree }\end{array}$ & $\begin{array}{l}\%(n / N) \text { strongly } \\
\text { disagree }\end{array}$ & \\
\hline Made to feel wasting the crew's time & $52 \%(17 / 33)$ & $38 \%(25 / 66)$ & $0.28(-6$ to 31$)$ \\
\hline
\end{tabular}

times compared with the ambulance service as a whole. The study might therefore have been less likely to find an impact on these measures than at other sites.

\section{Reliability of patient satisfaction follow up}

Patient satisfaction measures tend to overestimate satisfaction. ${ }^{27}$ In this study this effect should have been found in both groups and therefore it is unlikely to have led to any bias in the comparisons presented.

\section{Case recruitment}

The power of the study was reduced because of lower recruitment to study groups than anticipated. This occurred due to unexpectedly high rates of absence of trained crews during the study period and non-participation in the study when trained crew members were "driving" rather than "attending" appropriate patients. We had aimed to recruit

\section{Key messages}

- The introduction of "Treat and Refer" protocols did not lead to an increase in the number of patients left at the scene.

- Increased job cycle times associated with the use of "Treat and Refer" protocols may lead to less ambulance availability for response to other more serious calls.

- Protocols were used by all the crew members trained in their use, although not for all appropriate cases.

- Overall, documentation of clinical assessments was higher in the intervention group than in the control group.

- Concerns were identified with the safety of current usual practice and of practice using the protocols.

- Patients attended by crews trained in the use of the "Treat and Refer" protocols expressed higher levels of satisfaction with some aspects of care-particularly those related to communication of advice-than those attended by crews acting according to their usual practice.

- The need to develop the 999 service to improve the quality and appropriateness of service provided to patients is widely recognised, but this study confirms that changing practice is complex and effects sometimes unanticipated.
530 patients to each arm of the study but, in the event, this was only reached in the control group with half that number recruited to the intervention arm. With this number we would have been $75 \%$ certain of detecting a difference of $9 \%$ in non-conveyance at the 5\% level. The observed difference was only $1 \%$, which was not statistically significant and was not considered by the research team to be of any clinical or operational significance.

\section{Impact of introduction of protocols}

No impact on conveyance rates was identified. However, there was some evidence to suggest changes in practice that may have been masked by the overall result-most noticeably, the increased time on scene spent with patients in the intervention group. The increased time may indicate improved quality of care, supported by more thorough documentation of observations for patients in the intervention group and increased levels of satisfaction of intervention group patients.

If the increased time spent on scene noted in this study proved to be a persistent effect, a considerable impact would be made on operational performance of an ambulance service. With no journeys saved and an increased job cycle time, ambulances would be tied up for longer and availability for primary response to new emergency calls might be affected. In addition, in this study protocols were not used to their full potential, with usage variable between crew members. Crews' views and attitudes towards the new intervention have been explored in a qualitative study that was undertaken alongside the quantitative study reported here. ${ }^{28}$ If protocols were used to their full potential, the operational impact of increased job cycle times would be increased. Although care may be more appropriate, the operational implications of this need to be considered by ambulance services.

\section{Conclusions}

The necessity to develop the 999 service to improve the quality and appropriateness of service provided is widely recognised, but this study confirms the complexities involved in doing this. Although the trial showed that protocols for this purpose were used by crews and were acceptable to patients, the anticipated operational benefits were not demonstrated and safety concerns were identified. The lessons learned about the design and implementation of "Treat and Refer" protocols are valuable for taking the work forward, but to fully realise the potential benefits of this innovative change in service delivery these issues will need to be addressed in further research and/or service development work. 


\section{ACKNOWLEDGEMENTS}

The authors are grateful to participating LAS crews and managers, to the members of the Clinical Panel and the Project Advisory Group, as well as the patients included in the study.

\section{Authors' affiliations}

H Snooks, W Y Cheung, Clinical School, University of Wales Swansea, UK

N Kearsley, J Dale, Centre for Primary Health Care Studies, University of Warwick, UK

M Halter, London Ambulance Service NHS Trust, London, UK

J Redhead, Ealing Hospitals NHS Trust, London, UK

This study was funded by the London Region NHS Executive through their Organisation and Management research funding programme; total value of grant $£ 100000$.

HS and JD conceived the study, designed the trial, and gained research funding. HS led the trial with JD acting as principal academic advisor. NK coordinated the study and $\mathrm{MH}$ acted as the main liaison point with the ambulance service. NK was responsible for data collection, coding and input with MH assisting with data gathering. Analysis was carried out by NK, MH, HS and WYC with WYC responsible for statistical analysis. JD and JR provided research and clinical advice throughout the project. HS drafted the manuscript with all authors contributing comments and revisions. HS takes responsibility for the paper as a whole.

Papers were presented from this study at Ambex, June 2001 and Ambex, June 2002, both held in Harrogate, UK.

\section{REFERENCES}

1 Department of Health Government Statistical Service. Statistical Bulletin. Ambulance Services, England: 1998-9, Bulletin 1999/16, 1999.

2 Snooks H, Wrigley H, George S, et al. Appropriateness of use of emergency ambulances. J Accident Emerg Med 1998;15:212-8.

3 Chen JC, Bullard MJ, Liaw SJ. Ambulance use, misuse, and unmet needs in a developing emergency medical services system. Eur J Emerg Med 1996;3:73-8.

4 O'Leary C, Bury G, McCabe M, et al. Ambulance-user analysis in an accident and emergency department. Ir Med J 1987;80:422-3.

5 Rademaker AW, Powell DG, Read JH. Inappropriate use and unmet need in paramedic and nonparamedic ambulance systems. Ann Emerg Med 1987; 16:553-6.

6 Morris DL, Cross AB. Is the emergency ambulance service abused? BMJ 1980;3:121-3

7 Snooks H, Williams S, Crouch R, et al. NHS emergency response to 999 calls: alternatives for cases that are neither life-threatening nor serious. BMJ 2002;325:330-3
8 Department of Health. Reforming emergency care. First steps to a new approach, Winter And Emergency Services Capacity Planning Team. London: Stationery Office, 2001

9 NHS Executive Steering Group. Review of ambulance performance standards. London: Department of Health, 1996.

10 Chapman R. Transporting patients. London: NHS Executive, 1997.

11 Hunt J, Gratton MC, Campbell JP. Prospective determination of medical necessity for ambulance transport by on-scene triage abilities. Acad Emerg Med 1999:6:447(abstract).

12 Sasser SM, Brokaw M, Blackwell TH. Paramedics vs emergency physician decisions regarding the need for emergency department evaluation. Acad Emerg Med 1998;5:391 (abstract)

13 Hauswald M. Can paramedics safely decide who does not need ambulance transport or emergency department care? Acad Emerg Med 1998:5:390(abstract).

14 Ferrall SJ, Richards JR. A prospective study of the triage abilities of emergency medical services personnel. Acad Emerg Med 1998;5:390.

15 Santoro JP, Smith P, Mader TJ, et al. Accuracy of field diagnosis by paramedics. Acad Emerg Med 1998;5:390(abstract).

16 Suserud BO, Haliamae. H Nurse competence: advantageous in pre-hospital emergency care? Accid Emerg Nurs 1999;7:18-25.

17 Suserud BO, Wallman-C:son KA, Haljamae H. Assessment of the quality improvement of prehospital emergency care in Sweden. Eur J Emerg Med 1998;5:407-14.

18 Schmidt T, Atcheson R, Federiuk, et al. Evaluation of protocols allowing emergency medical technicians to determine the need for treatment and transport. Acad Emerg Med 2000;7:663-9.

19 Hauswald M. Can paramedics safely decide who does not need ambulance transport or emergency department care? Acad Emerg Med 1998;5:390(abstract)

20 Sasser SM, Brokaw M, Blackwell TH. Paramedic vs emergency physician decisions regarding the need for emergency department evaluation. Acad Emerg Med 1998:5:391 (abstract).

21 Snooks HA, Halter M, Hartley-Sharpe C, et al. On-scene alternatives for emergency ambulance crews attending patients who do not need to travel to the Accident and Emergency Department: a review of the literature. Emerg Med J 2004;21:212-5.

22 Wolford RW, Tisol W, Vasilenko P, et al. Prospective evaluation of criteria allowing paramedics to treat and release patients presenting with hypoglycaemia. Prehospital and Disaster Medicine 1996;July-September

23 Billitier A IV, Lerner EB, Lance D, et al. Can paramedics safely treat and release hypoglycaemic patients in the field? Acad Emerg Med 1998:5:139(abstract).

24 Anon. Albuquerque halts EMS triage program. EMS Insider 1999.

25 Snooks H, Kearsley N, Dale J, et al. New models of care for 999 callers with conditions that are neither life-threatening nor serious: results of a national survey. Prehospital Immediate Care 2000;4:180-2.

26 Carey RC, Seibert JH. A patient survey system to measure quality improvement questionnaire reliability and validity. Med Care 1993;31:834-45.

27 Jenkinson C, Coulter A, Bruster S, et al. Patients' experiences and satisfaction with health care: results of a questionnaire study of specific aspects of care. Qual Saf Health Care 2002; 11:335-9.

28 Snooks H, Dale J, Kearsley N, et al. Development and impact of emergency ambulance 'Treat and Refer' protocols for non-serious 999 patients, Final report to London Region NHS Executive, October, 2001. 